\title{
Lack of tolerance to cyclopropane and cross-tolerance to halothane in rats
}

Cyclopropane requirement (MAC) in rats was determined before, during, and after repeated exposure to anaesthetic concentrations of cyclopropane and halothane for one hour every day for 20 and 30 days, respectively. MAC values during and after exposure ranged from 9310103 per cent (mean $=99$ per cent) of control values, which indicates a lack of significant colerance to cyclopropane or a cross-tolerance between cyclopropane and halothane.

\section{Key words}

ANAESTHETICS, GASES: cyclopropane, halothane; INTERACTIONS: cross-tolerance, tolerance; PHARMACOKINETICS; tolerance; POTENCY, ANAESTHETIC: minimum alveolar concentration; TOLERANCE.

The occurrence of tolerance and cross-tolerance to opioids, barbiturates, and alcohol is a phenomenon commonly observed in clinical practice. Recently, alcohol has been shown to induce a tolerance to isoflurane in animals. 'Another report by Chalon et $\mathrm{al}^{2}{ }^{2}$ suggests that tolerance and cross-tolerance may occur after repeated exposure to inhalational anaesthetics. The development of pharmacologic tolerance to general anaesthetics has important clinical implications, particularly in regard to prolonged

From the Department of Anesthesiology, University of Florida College of Medicine, and the Anesthesiology Service, Veterans Administration Medical Center, Gainesville, Florida.

Address correspondence to: Dr. Edwin S. Munson, Department of Anesthesiology, University of Kentucky Medical Center, Lexington, Kentucky, 40536. and repeated anaesthetic procedures. In order to assess the effect of repeated anaesthetic exposure on tolerance and cross-tolerance, cyclopropane requirement (MAC) was measured in rats before, during, and after daily exposures to either cyclopropane or halothane. In contrast to previous murine studies that assessed the depth of anaesthesia by the righting reflex, the level of anaesthesia was quantified according to the response to tail clamping over a range of calculated alveolar concentrations of cyclopropane.

\section{Methods}

Cyclopropane requirement (MAC) was determined in 20 Sprague-Dawley male rats $(250-300 \mathrm{gm})$ as previously described ${ }^{3-4}$ Responses to tail clamping with a surgical forceps were noted in each animal during inhalation of cyclopropane. Inspired concentrations of cyclopropane ranging from 12 to 25 per cent, in oxygen, were derived from calibrated flowmeters. Alveolar cyclopropane concentrations were calculated from inspired values and corrected for dilution by water vapour at body temperature. Gases were delivered at a rate of $2.5 \mathrm{~L} \cdot \mathrm{min}^{-1}$ into a bank of transparent chambers $(0.2 \mathrm{~L})$ that covered each animal's head and thorax. Anaesthesia was induced with 25 per cent cyclopropane; after ten minutes the concentration was reduced to 20 per cent for another five minutes. The tail was then clamped and the response was noted. This procedure was repeated, except the concentration was reduced in one per cent decrements until the animal responded by moving. MAC is defined as the alveolar (anaesthetic) concentration that prevented movement in respone to tail clamping in 50 per cent of the animals. Colonic temperature was measured with a telethermistor probe and was maintained at $37 \pm 0.5^{\circ} \mathrm{C}$ by external heating. All experiments were performed during daylight hours. 
After control measurements, animals were divided randomly into two equal groups. Each group of animals was exposed together to delivered concentrations of either 15 per cent cyclopropane or 1.5 per cent halothane for one hour every day for 20 and 30 days, respectively. The anaesthetics were delivered in oxygen at rates equal to three times the volume of the animals' containers. Several layers of soda lime absorbent granules were placed on the floor of the containers. Overflow gases were scavenged by a laboratory hood. The animals quickly became inactive and appeared asleep during these exposures; no tail clamping was performed during these periods. Cyclopropane MAC was redetermined after 14 and 20 exposures to cyclopropane and after 14 and 30 exposures to halothane. The number of exposures to halothane, before the final determination of cyclopropane MAC, was increased to 30 when the apparent absence of change in MAC after 20 exposures was observed.

Results were analyzed with the standard method of probit transformation of per cent response plotted against the log dose of cyclopropane. With this method, MAC $\left(E_{50}\right)$ and the standard deviation (ED 16-85) were obtained. Differences between MAC values were compared by analysis of variance.

\section{Results}

Dose-response data for the control, cyclopropane, and halothane groups are shown in Table I. MAC values (mean $\pm S D$ ), calculated by probit transformation, are presented in Table II. The values during and after anaesthetic exposures ranged from 93 to 103 per cent of control (mean 99 per cent) and, thus showed no significant $(p>0.27)$ tolerance to cyclopropane or cross-tolerance between halothane and cyclopropane. No withdrawal behaviour, such as seizure, was observed in any animal in the immediate postanaesthetic period. Two animals were lost from the halothane group before the final measurements were made. One animal apparently escaped from his cage and the other was found dead in his cage.

\section{Discussion}

Tolerance is a phenomenon commonly observed with ethanol, opioids, and hypnotics and is defined as an increase in the amount of an agent required to achieve the same end point after repeated exposure to that agent. Inhalational anaesthetics could
TABLE I Percentage of animals moving in response to tail clamping during daily, one-hour exposures to cyclopropane

\begin{tabular}{lrrrrrr}
\hline \multicolumn{7}{c}{ Cyclopropane (per cemi) } \\
\cline { 2 - 7 } & 14 & 15 & 16 & 17 & 18 & 19 \\
\hline Control & 95 & 85 & 65 & 35 & 10 & 5 \\
Cyclopropane & & & & & & \\
$\quad$ 14th day & 100 & 80 & 40 & 20 & 0 & - \\
20th day & 75 & 50 & 37.5 & 25 & 25 & 12.5 \\
Halothane & & & & & & \\
14th day & 90 & 90 & 90 & 50 & 20 & 10 \\
30th day & 90 & 80 & 70 & 50 & 20 & 10 \\
\hline
\end{tabular}

produce an acquired pharmacologic tolerance by several mechanisms, such as disposition and pharmacodynamics. Dispositional tolerance results from altered pharmacokinetics so that reduced drug concentrations are required at the site of action. Drug metabolism and enzyme induction are important mechanisms that can alter drug concentrations. Pharmacodynamic tolerance is an adaptive change; the drug concentration is unchanged, but the response is less intense. This is the mechanism that is considered to be relevant to the present work.

Cross-tolerance, or cross-dependence, is defined as the ability of one drug to induce and maintain a state of tolerance to another drug. In general, drugs that induce tolerance have similar pharmacologic effects but not necessarily similar molecular composition. Johnstone et al. ${ }^{1}$ have shown crosstolerance between ethanol and isoflurane, but until recently there have been no reports of such interactions between inhalational anaesthetics.

Eger, Saidman, and Brandstater, ${ }^{5}$ in their original description of MAC, tested the reproducibility of halothane requirement in dogs during multiple

TABLE II MAC values calculated from data shown in Table I using probit-log cyclopropane concentration analysis

\begin{tabular}{llll}
\hline $\begin{array}{l}\text { Day of } \\
\text { Exposure }\end{array}$ & $\begin{array}{l}\text { Number of } \\
\text { Animals }\end{array}$ & Cyclopropane & Halothane \\
\hline Control & 20 & $16.4 \pm 1.5$ & $16.4 \pm 1.5$ \\
14th & 10 & $15.9 \pm 1.1$ & $16.9 \pm 1.8$ \\
20th & 8 & $15.4 \pm 2.9$ & \\
30th & 10 & & $16.6 \pm 2.0$
\end{tabular}

All values represent means $\pm \mathrm{SD}$.

Analysis of variance showed no significant differences $(p>$ 0.27 ). 
eight-hour exposures. Mean deviation of MAC in the same animals was less than eight per cent. Thus, these investigaters showed no evidence of acute acquired anaesthetic tolerance. Another study, which also evaluated tail-clamp responses over a prolonged period, provides additional support for the constancy anaesthetic requirement. Munson, Martucci, and Smith ${ }^{4}$ quantified halothane and cyclopropane requirements at four-hour intervals over a period of 24 hours in rats under conditions of fixed environmental control. Both anaesthetics showed significant circadian variation with a periodic retum of MAC to control values after 24 hours but not a progressive increase in values as wold be anticipated with an acquired tolerance.

Smith and his colleagues tested the development of both acute and chronic tolerance to other inhalational anaesthetic agents. ${ }^{6-8}$ Using relatively brief exposures (64 minutes), these authors found an eight and 18 per cent increase in the $\mathrm{ED}_{50}$ to abolish the righting reflex to nitrous oxide and ethylene (and helium), respectively. ${ }^{6}$ However, neither cyclopropane alone nor nitrous oxide plus helium induced acute tolerance. Rather, cyclopropane requirement decreased 12 per cent after a one-hour exposure. When Smith et al. ${ }^{7}$ continuously exposed mice to 50 per cent nitrous oxide for two to three weeks -24 times the total duration of the present study - a tolerance to nitrous oxide developed (a 12 per cent increase in the $\mathrm{ED}_{50}$ ). Similarly, cross-tolerance to both cyclopropane and isoflurane also was found after two-week exposures to nitrous oxide. However, mice similarly exposed to isoflurane showed neither tolerance nor cross-tolerance to nitrous oxide. The withdrawal seizures described by these investigators ${ }^{8}$ were not observed in the present study.

Recently, Chalon et al. ${ }^{2}$ reported tolerance in mice after 13 brief exposures to halothane. In addition, they found cross-tolerance between isoflurane and enflurane and between halothane and isoflurane. The findings of the present study differ from the murine studies described above and, although the reasons for this discrepancy are not clear, major differences are apparent in the methodologies. Specific differences between these works are as follows. Previous studies employed mice rather than rats and the anaesthetic agents employed were of moderate solubility in blood. The latter tends to yield imprecise estimates of anaesthetic depth since anaesthetic uptake can vary at fixed inspired concentrations, which may influence the resultant alveolar anaesthetic concentration (partial pressure) and, therefore, the depth of anaesthesia. Cyclopropane was used in the present study because of its low blood solubility and, therefore, a more accurate calculation of alveolar concentration. More importantly, previous workers used the righting reflex as a standard of potency, whereas the present study used MAC, a more precise estimate of anaesthetic depth. Finally, the lack of a standard period of exposure makes interpretation of all these data difficult. Exposures have ranged from one hour to three weeks, and some have been intermittent and extended over a month. Daily one-hour exposures for 20 to 30 days were chosen as a regimen that might resemble the clinical situation of repeated anaesthetic procedure. It is concluded that repeated exposure to inhalational anaesthetics does not result in acquired pharmacologic tolerance or crosstolerance.

\section{References}

1 Johnstone RE, Kulp RA, Smith TC. Effects of acute and chronic ethanol administration on isoflurane requirement in mice. Anesth Analg 1975; 54: 277-81.

2 Chalon J, Tang C-K, Roberts $C$ et al. Murine auto- and cross-tolerance to volatile anaesthetics. Can Anaesth Soc J 1983; 30: 230-4

3 Munson ES, Hoffman, JC, DiFazio CA. The effects of acute hypothyroidism and hyperthyroidism on cyclopropane requirement (MAC) in rats. Anesthesiology 1968; 29: 1094-8.

4 Munson ES, Martucci RW, Smith RE. Circadian variations in anesthetic requirement and toxicity in rats. Anesthesiology 1970; 32: 507-14.

5 Eger EI II, Saidman LJ, Brandstater B. Minimum alveolar anesthetic concentration: A standard of potency. Anesthesiology 1965; 26: 756-63.

6 Smith RA, Winter PM, Smith M, Eger EI II. Rapidly developing tolerance to acute exposures to anesthetic agents. Anesthesiology 1979; 50: 496-500.

7 Smith RA, Winter PM, Smith M, Eger EI II. Tolerance to and dependence on inhalational anesthetics. Anesthesiology 1979; 50: 505-9.

8 Smith RA, Winter PM, Smith $M$, Eger EI II. Convulsions in mice after anesthesia. Anesthesiology 1979; 50: 501-4. 
Résumé

On a déterminé les besoins en cyclopropane (MAC) dans deux groupes de rats avant, pendant et après des administrations répétées de concentrations anesthésiques de cyclopropane et d' halothane durant une heure chaque jour, pendant 20 et 30 jours respectivement. Les valeurs du MAC pendant et après ces administrations ont varié entre 93 et 103\% (moyenne: $99 \%$ ) des valeurs contrôles, ce qui indique que ces administrations répétées $n^{\prime}$ ont pas déclenché de tolérance au cyclopropane ou de tolêrance croisée à l'égard de l' halothane. 